\title{
Fracture Toughness in Metal Matrix Composites
}

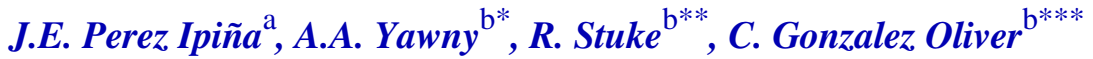 \\ ${ }^{\mathrm{a}}$ Grupo Mecánica de Fractura, U.N. Comahue/Conicet, Buenos Aires 1400, 8300 \\ Neuquén, Argentina \\ ${ }^{\mathrm{b}}$ Centro Atómico Bariloche, CNEA, 8400 Bariloche, Argentina
}

Received: February 29, 2000; Revised: July 31, 2000

\begin{abstract}
Evaluations of the fracture toughness in metal matrix composites (Duralcan reinforced with 15\% of $\mathrm{Al}_{2} \mathrm{O}_{3}$ and $\mathrm{SiC}$ ) are presented in this work. The application of Elastic Plastic Fracture Mechanics is discussed and the obtained values are compared with the ones obtained by means of Linear Elastic Fracture Mechanics. Results show that $\mathrm{J}_{\mathrm{IC}}$ derived $\mathrm{K}_{\mathrm{JC}}$ values are higher than the corresponding values obtained by direct application of the linear elastic methodology. The effect of a heat treatment on the material fracture toughness was also evaluated in which the analyzed approaches showed, not only different toughness values, but also opposite tendencies. A second comparison of the JIC and $\mathrm{KJC}_{\mathrm{JC}}$ values obtained in this work with toughness values reported in the literature is presented and discussed.
\end{abstract}

Keywords: metal matrix composite, elastic plastic feature mechanics, feature toughness, experimental techniques

\section{Introduction}

Metal matrix composites (MMC) are materials made from the dispersion of a ceramic phase, typically $\mathrm{SiC}$ or $\mathrm{Al}_{2} \mathrm{O}_{3}$ fibers or particles, in order to improve the mechanical and physical properties of the matrix. In the particular situation of Aluminum MMCs, both pure $\mathrm{Al}$ and alloys are employed. Continuous fibers (Continuous metal matrix composites CMMC) as well as short fibers and particles (Discontinuous Aluminum reinforced DAR) are employed.

The production and use of composite materials is under intensive development because of the interesting physical and mechanical properties that these materials present ${ }^{1-6}$ and also due to the possibility to manipulate them by means of the variation of the type and proportion of the reinforcement employed as well as the type of the metallic matrix. Materials with designed mechanical (yield stress, elastic modulus, etc) and physical (thermal expansion coefficient, resistivity, thermal conductivity, etc) properties can be produced in this way.

The specific yield stress that can be obtained in these materials make them very attractive for high temperature applications where the conventional heat treated alloys are useless as a consequence of the dissolution of the precipitates that give them good mechanical properties at moderate temperatures. However, the low fracture toughness that these materials exhibit remains as their major drawback.

e-mail: "apipina @uncoma.edu.ar; *yawny@cab.cnea.edu.ar;

**stuke@cab.cnea.edu.ar; ***gon@cab.cnea.edu.ar
This problem has reduced its expansion in applications to structural uses. A great effort has been done on this field trying to understand the mechanisms that control the fracture process but, as a consequence of the complexity of the problem, not enough understanding has been achieved up to date.

Many works about fracture toughness in MMC are found in the literature, specially based in DAR of 6XXX and $2 \mathrm{XXX}$ Aluminum alloys reinforced with $\mathrm{SiC}$ or $\mathrm{Al}_{2} \mathrm{O}_{3}$ particles. One of the most studied materials is Duralcan from Alcan ${ }^{7}$ because it is produced in mass scale by a low cost industrial process. Most data found in the literature are expressed in terms of $\mathrm{K}$, the linear elastic parameter. In the review of Mortensen ${ }^{8}$ a huge quantity of results obtained by application of linear elastic fracture mechanics is cited. They are based on the ASTM E- $399^{9}$ procedure as well as on the measurement of the crack energy release rate $\mathrm{G}_{\mathrm{C}}{ }^{10}$. Mortensen ${ }^{8}$ comments on the corresponding justifications and, in some cases also, on the limitations given by the use of procedures: that did not used a precrack induced by fatigue, that calculated $\mathrm{K}$ from maximum load values or that they used tests with chevron notches and /or short rod specimens ${ }^{11}$. Beck et al. ${ }^{12}$ also used the Equivalent Energy Method, following ASTM E992 ${ }^{13}$. Most of the published results correspond to low toughness values. 
Evaluations of fracture toughness of DURALCAN MMC are presented in this work. The applicability of elastic-plastic fracture mechanics is discussed. The obtained values are compared with the cited in the literature by application of linear elastic fracture mechanics. The incidence of a heat treatment on the fracture toughness is also discussed.

\section{Material and Method}

Two MMC materials provided by DURALCAN: $\mathrm{Al} 606115 \% \mathrm{Al}_{2} \mathrm{O}_{3}$ and $\mathrm{Al}-\mathrm{Si}$ alloy $15 \% \mathrm{SiC}$ were studied. The tests were made in the as received condition and, for two specimens, also with a heat treatment that consisted in annealing to $340^{\circ} \mathrm{C}$ for $24 \mathrm{~h}$ with heating and cooling rates of $1{ }^{\circ} \mathrm{C} / \mathrm{min}$.

Compact tension specimens with a $1 / 2$ inch thickness $(1 / 2 \mathrm{~T}-\mathrm{CT})$ were machined from round bars of $50 \mathrm{~mm}$ in diameter. Table 1 shows the specimens dimensions.

Fatigue precracks were grown by means of application of variable load cycles in a servo-hydraulic MTS-810 machine under displacement control, with frequencies between 10 to $30 \mathrm{~Hz}$. Chevron notches were used in some specimens in order to enhance the initiation of the fatigue crack.

The tests were made also in the MTS-810 machine, using displacement control with a load point displacement rate of $0.1 \mathrm{~mm} / \mathrm{min}$. Load vs. Load point displacement (P $v s . \delta$ ) and amplified Load vs. mouth opening displacement (P vs. V) plots were obtained. The last one was obtained only during the partial unloadings (more than 20 in each specimen). In this way the unloading compliance method was employed.

The tests were made at room temperature and, in some cases for Duralcan reinforced with $\mathrm{Al}_{2} \mathrm{O}_{3}$, at a higher temperature, near $50{ }^{\circ} \mathrm{C}$.

Values of $\mathrm{J}_{\mathrm{IC}}$ and $\mathrm{J}-\mathrm{R}$ were obtained following the ASTM E-813:89 14 and ASTM E:1152:89 ${ }^{15}$ standards. From the obtained $\mathrm{J}_{\mathrm{IC}}$, the equivalent $\mathrm{K}, \mathrm{K}_{\mathrm{IC}}$, were calculated by means of the following equation, given by the standard

$$
\mathrm{K}_{\mathrm{JC}}=\sqrt{\mathrm{J}_{\mathrm{IC}} \mathrm{E}^{\prime}}
$$

$\mathrm{K}_{\mathrm{Pmax}}$ values were also calculated using the equations given by ASTM E- $399^{9}$, with the initial dimensions of the specimens and the maximum load values.

Fractographic analysis were made to characterize the fracture mode.

\section{Results}

The necessary precracking loads to initiate and propagate the cracks where high (in some cases higher than 70\% of the maximum load of the fracture test). With lower loads the cracks did not grow.
Figure 1 shows a $\mathrm{P} v s$. $\delta$ record corresponding to specimen Dur21 while Fig. 2 shows the $\mathrm{P} v s$. V records of the partial unloadings of the same specimen. On the other hand, an R-Curve J- $\delta$ a corresponding to the specimen Dur2 can be seen in Fig. 3. All the tested specimens showed similar records. These figures undoubtedly confirm the existence of an elastic-plastic behavior in these materials.

Table 1 shows all the obtained results.

Figure 4 shows a fractography of a tested specimen where ductile mechanisms are clearly seen.

\section{Discussion}

The feasibility of fatigue precracking was proved. The fatigue precrack observation was only possible with very careful polished surface.

The Chevron notches used in some specimens to enhance the initiation of the fatigue crack did not proved to be useful.

The process of growing fatigue precracks in these materials is often cited as difficult ${ }^{8}$, moreover, it was also proposed the use of acute nochtes $(30-50 \mu \mathrm{m})^{16}$ instead of fatigue precracks. In coincidence with other re-

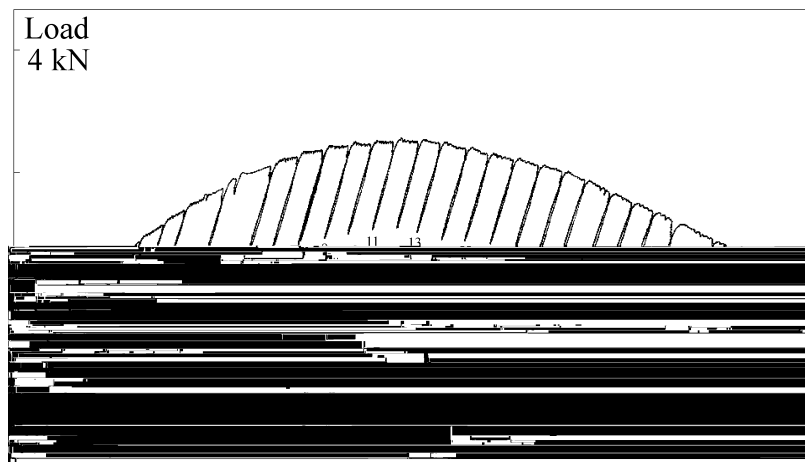

Figure 1. Load vs. load point displacement $(\mathrm{P} v s . \delta)$ record for specimen Dur 21.

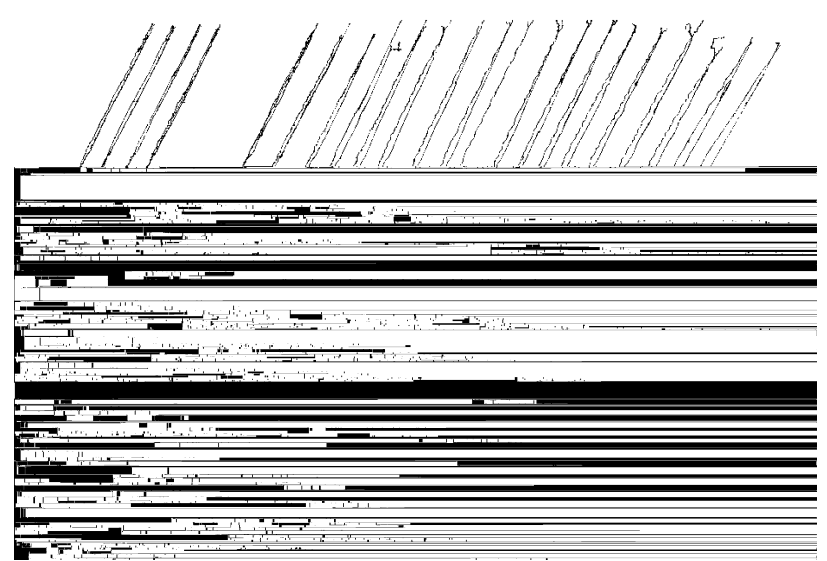

Figure 2. Amplified load vs. mouth opening displacement ( $\mathrm{P} v s . \mathrm{V})$ records corresponding to the partial unloadings shown in the $\mathrm{P} v s$. $\delta$ plot (Fig. 1) for specimen Dur 21. 


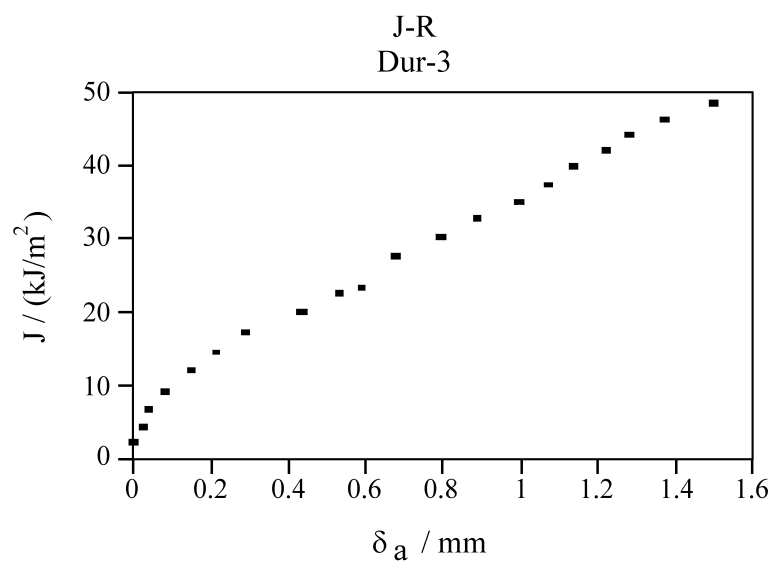

Figure 3. Crack growh resistance curve J - $\delta$ a for specimen Dur 2.

searchers ${ }^{12,17}$, we consider that, in spite of not having done comparative experiments between fatigue precracked specimens and notched ones, the standardized methods must be followed. The equipment and techniques normally available in a fracture mechanics laboratory are sufficient to fatigue precrack the MMC fracture toughness specimens.

Many data found in the literature are expressed in terms of $\mathrm{K}$, the linear elastic parameter. In his excellent review, Mortensen ${ }^{8}$ cites a huge quantity of results obtained by application of Linear Elastic fracture mechanics, using more or less strictly the ASTM E-399 procedure, as well as measuring $\mathrm{G}_{\mathrm{C}}{ }^{10}$ and afterwards calculating $\mathrm{K}$. Mortensen also mentions the corresponding justifications (and in some cases the limitations) given by the use of these procedures without fatigue precracking and with the calculation of $\mathrm{K}$ from maximum load values, as well as tests with chevron

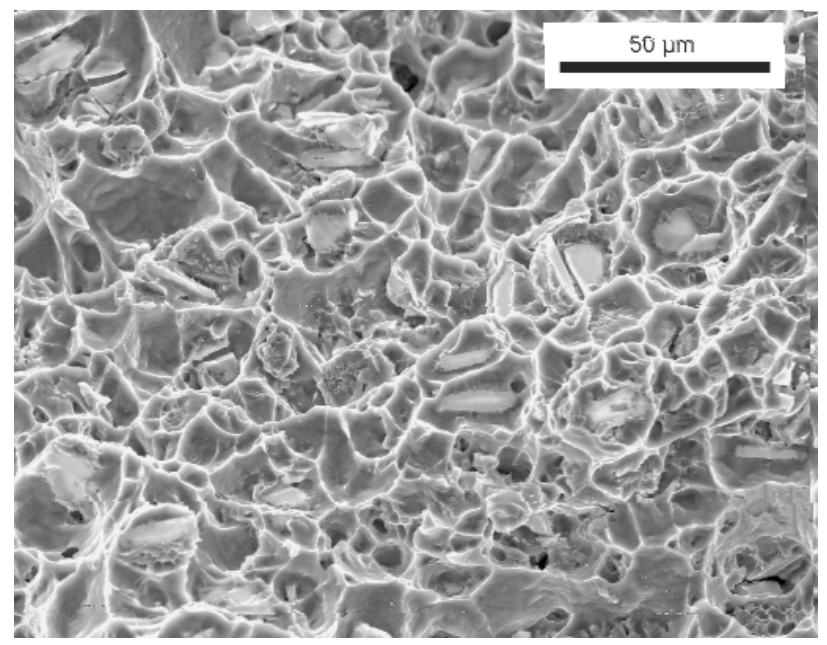

Figure 4. SEM fractography of Dur 23 specimen.

notches and/or short rod specimens ${ }^{11}$. Beck et al. ${ }^{12}$ also used, besides ASTM E399 standard, the Equivalent Energy Method, following ASTM E992 ${ }^{13}$, but both values did not appreciably differ.

It must be considered that when the specimen shows non-linearity in the load-displacement record, it can be as a consequence of plastic deformation or any other mechanism present near the crack tip, non-linear material $\sigma-\varepsilon$ behavior, stable crack growth or any combination between them. The $\mathrm{K}_{\mathrm{IC}}$ value measured in this way is not representative of the fracture toughness because the condition for the Stress Intensity Factor to describe the stress and strain fields near the crack tip (linear relation between stress and strain and small scale yielding) have been violated ${ }^{18}$. An elastic plastic or an R-curve methodology is then needed to be applied for the analysis.

Table 1.

\begin{tabular}{llcccccccc}
\hline & Description & $\begin{array}{c}\mathrm{T} \\
\left({ }^{\circ} \mathrm{C}\right)\end{array}$ & $\begin{array}{c}\mathrm{W} \\
{[\mathrm{mm}]}\end{array}$ & $\begin{array}{c}\mathrm{B} \\
{[\mathrm{mm}]}\end{array}$ & $\begin{array}{c}\mathrm{a}_{0} \\
{[\mathrm{~mm}]}\end{array}$ & $\mathrm{a} / \mathrm{W}$ & $\begin{array}{c}\mathrm{J}_{\mathrm{IC}} \\
{\left[\mathrm{KJ} / \mathrm{m}^{2}\right]}\end{array}$ & $\begin{array}{c}\mathrm{K}_{\mathrm{JC}} * \\
{[\mathrm{MPa} \sqrt{\mathrm{m}}]}\end{array}$ & $\begin{array}{c}\mathrm{K}_{\mathrm{Pmax}} \\
{[\mathrm{MPa} \sqrt{\mathrm{m}}]}\end{array}$ \\
\hline Dur 2 & DURALCAN: Al6061 15\% $\mathrm{Al}_{2} \mathrm{O}_{3}$ & $\mathrm{RT}$ & 25.43 & 12.75 & 15.66 & 0.62 & 19 & 43.6 & 16.7 \\
Dur 3 & Idem Dur 2 & $\mathrm{RT}$ & 25.58 & 12.75 & 18.47 & 0.72 & 16 & 40.0 & 18.0 \\
Dur 4 & Idem Dur 2 & $\mathrm{RT}$ & 25.52 & 12.75 & 18.16 & 0.71 & 16 & 40.0 & 14.6 \\
Dur 6 & Idem Dur 2 & $\mathrm{RT}$ & 25.31 & 12.70 & 18.38 & 0.73 & 17 & 41.2 & 17.5 \\
Dur 1 & Idem Dur 2 + annealing a 338 ${ }^{\circ} \mathrm{C}$ & $\mathrm{RT}$ & 25.46 & 12.70 & 17.73 & 0.70 & 27 & 52.0 & 14.8 \\
Dur 5 & Idem Dur 1 & $\mathrm{RT}$ & 25.44 & 12.70 & 18.41 & 0.72 & 24 & 49.0 & 15.7 \\
Dur 7 & Idem Dur 2 & 50 & 25.37 & 12.68 & 15.98 & 0.63 & 13 & 36.1 & 18.1 \\
Dur 8 & Idem Dur 2 & 50 & 25.26 & 12.71 & 14.86 & 0.59 & 18 & 42.4 & 19.0 \\
Dur 9 & Idem Dur 1 & 50 & 25.34 & 12.71 & 13.25 & 0.52 & 27 & 52.0 & 17.8 \\
Dur 20 & DURALCAN Al-Si with 15\% SiC & $\mathrm{RT}$ & 25.42 & 12.71 & 15.06 & 0.59 & 20 & 44.7 & 19.1 \\
Dur 21 & Idem Dur 20 & $\mathrm{RT}$ & 25.57 & 12.76 & 14.39 & 0.56 & 26 & 51.0 & 19.9 \\
Dur 23 & Idem Dur 20 + annealing 346 ${ }^{\circ} \mathrm{C}$ & $\mathrm{RT}$ & 25.57 & 12.73 & 12.75 & 0.50 & 34 & 58.3 & 16.7 \\
\hline
\end{tabular}

* Values calculated for $\mathrm{E}=100 \mathrm{GPa}$. 
As it can be seen in Fig. 1, the fracture toughness tests have shown unquestionably an elastic plastic behavior with ductile growing mechanism. As a consequence, we decided to use J-R curves and $\mathrm{J}_{\mathrm{IC}}$ determinations. Ductile mechanisms in both materials were observed (Fig. 4).

By obvious reasons, it is of great interest to make a comparative analysis with the corresponding values cited in the literature, generally given in terms of $\mathrm{K}$. In the cases of the non-linear behavior found in our tests, $\mathrm{J}_{\mathrm{IC}}$ can be determined and then translated to $\mathrm{K}$ values by means of Eq. (1). These values are shown in Table 1, as well as the ones corresponding to maximum load values. As an example, the specimen Dur1 is analyzed. For E $=100 \mathrm{GPa}$, an equivalent $\mathrm{K}_{\mathrm{JC}}$ of about $52.0 \mathrm{MPa} \sqrt{\mathrm{m}}$ is obtained, while $\mathrm{K}$ taken from maximum load value is $K_{P \max }=14.8 \mathrm{MPa} \sqrt{\mathrm{m}}$. This last value is the one that is cited as fracture toughness in some papers.

Some experimental difficulties are argued in order to determine elastic plastic parameters or R-Curves, that the stable crack growth initiation is near the maximum load point, and also that $\mathrm{K}_{\mathrm{Pmax}}$ is measured to use the values only comparatively, although it was not the real fracture toughness of the material. It is very important to discuss this point profoundly because the MMC materials are considered materials with brittle behavior. This is not true, at least for the materials tested in this work, as it can be seen in the records, the R-curves and in Table 1. In some specimens deformation occurred producing slow stable crack growth beyond $40 \%$ of the initial remaining ligament without any instability. This is in some way contradictory with the values given by many authors ${ }^{8,11,12}$, but we consider that it is because they have used some kind of linear elastic fracture mechanics instead of the elastic plastic.

All the specimens with a heat treatment consisting in heating until $340^{\circ} \mathrm{C}$ with rates of $1{ }^{\circ} \mathrm{C} / \mathrm{h}$ have shown a very important increasing in the $\mathrm{J}_{\mathrm{IC}}$ values. When the tendency was analyzed in terms of $K_{P \max }$, it was the opposite: the specimens with the heat treatment showed lower $\mathrm{K}_{\mathrm{Pmax}}$ values.

We consider very important to emphasize here that the measurement of maximum load values could lead to absolutely wrong conclusions when tendencies due to microstructure changes are analyzed. In Table 1 it can be observed that a heat treatment increases the material fracture toughness (50\% increase in $\mathrm{J}_{\mathrm{IC}}$ and $25 \%$ increase in $\mathrm{K}_{\mathrm{JC}}$ ), while the same tests analyzed by maximum load parameters $\left(\mathrm{K}_{\mathrm{pmax}}\right)$ indicate a small decrease in the toughness values. The application of linear elastic criteria could then induce to the wrong conclusion that an annealing treatment could decrease the fracture toughness.

The tests done at a temperature higher than room temperature $\left(48^{\circ} \mathrm{C}\right)$ in DURALCAN reinforced with $\mathrm{Al}_{2} \mathrm{O}_{3}$ did not show significant variations in fracture toughness. This could be masked due to the normal scatter in fracture toughness that this kind of materials presents.

\section{Conclusions}

a) Linear elastic fracture mechanics is not considered to be adequate to the type of materials that have been tested because they showed important non-linearities due to plastic deformation and stable crack growth.

b) Elastic plastic fracture mechanics is considered as the methodology to be applied. In this work J criterion was employed.

c) The $\mathrm{K}_{\mathrm{IC}}$ values estimated from the values of $\mathrm{J}_{\mathrm{IC}}$ are considerably higher than many $\mathrm{K}$ values reported in the literature for similar materials. This discrepancy could be imputed to the different experimental procedures to measure the fracture toughness (elastic plastic or linear elastic fracture mechanics). When linear elastic fracture mechanics was employed in our materials, the $\mathrm{K}_{\mathrm{Pmax}}$ values obtained were comparable to the ones reported in the literature.

d) We consider that the procedure normally employed by many authors of measuring $\mathrm{K}_{\mathrm{Pmax}}$, in spite of its simplicity, is not adequate and give very low fracture toughness values.

e) We have found an inverse tendency in the $K_{P \max }$ variation compared with the tendency in $\mathrm{J}_{\mathrm{IC}}$ when microstructural changes are analyzed. This could induce to wrong conclusions about the convenience of performing heat treatments.

f) The annealing heat treatments done in this work promoted an important increase in fracture toughness.

g) The fatigue precracking was possible and it resulted to be relatively simple, but the necessary loads to initiate and grow the cracks were considered high.

h) The $\mathrm{J}_{\mathrm{IC}}$ values measured at temperatures near $50^{\circ} \mathrm{C}$ did not show significant differences with respect to the room temperature ones.

\section{Acknowledgments}

To Guillermina Urretavizcaya for the experimental collaboration, to Dr. Boyd for the comments and to DURALCAN that supplied the material. This work was supported by Proyecto PID-BID 480 / SECYT-CONICET, and PIA 6376/96 / CONICET.

\section{References}

1. Abraham T. The U.S. Ceramic-Matrix Composites Market in The 1990's, JOM, v. 44, n. 6, p. 44-45, 1992.

2. Premkumar, M.K.; Hunt, W.H.; Sawtell, R.R. Aluminum Composite Materials for Multichip Modules, JOM, v. 44, n. 7, p. 24-28, 1992.

3.Zweben C. Metal-Matrix Composites for Electronic Packaging, JOM, v. 44, n. 7, p. 15-23, 1992. 
4. Allison, J.E.; Cole, G.S. Metal-Matrix Composites in The Automotive Industry: Opportunites and Challenges, JOM, v. 45, n. 1, p. 19-25, 1993.

5. Deve H.E.; McCullough, C. Overview: ContinuousFiber Reinforced Al Composites: A New Generation, JOM, v. 47, n. 7, p. 28-32, 1995.

6. Doychak, J. Metal and Intermetalic-Matrix Composites for Aerospace Propulsion and Power Systems, JOM, v. 44, n. 6, p. 46-51, 1992.

7.Duralcan Composites - Mechanical and Physical Property Data, Wrought Materials, SI Units: data information sheet released by Duralcan, 1990.

8. Mortensen, A. A Review of The Fracture Toughness of Particle Reinforced Aluminum Alloys. Proc. Int. Conf. Fabrication of Particulates Reinforced Metal Composites, Québec, Canada, p. 217-233, Sept. 1990.

9. ASTM E-399 Standard Test Method for Plane-Strain Fracture Toughness of Metallic Materials, Annual Book of ASTM Standards, v. 3, n.1, p. 506-536, 1992.

10. Daimaru, A.; Hata, T.; Taya, M. Recent Advances in Composites in the United States and Japan. ASTM STP 864, ASTM, p. 505-521, 1985.

11. Lewandowski, J.J.; Liu, C.; Hunt Jr., W.H. Processing and Properties for Powder Metallurgy Composites. P.Kumar et al., eds., TMS, p. 117-137, 1988.
12. Beck, Tan N.C.; Aikin Jr., R.M.; Briber, R.M. Fracture Toughness of Discontinuously Reinforced Al$4 \mathrm{Cu}-1.5 \mathrm{Mg} / \mathrm{TiB}_{2}$ Composites, Metallurgical and Materials Transactions A, v. 25, n. 11, p. 2461-2468, 1994.

13. ASTM E992-84 Standard Practice for Determination of Fracture Toughness of Steels Using Equivalent Energy Methodology. Annual Book of ASTM Standards, v. 3, n. 1, p. 796-801, 1992.

14. ASTM E-813:87. Standard Test for JIC. A Measure of Fracture Toughness. Annual Book of ASTM Standards: Section 3, v. 3, n. 1, p. 968-990, 1987.

15. ASTM E-1152:89. Standard Test Method for Determining J-R Curves. Annual Book of ASTM Standards, v. 3, n. 1, p. 847-857, 1992.

16. Raymond, L.; Jennings, J.A. Fracture Toughness of Thin Walled Cylinders Fabricated from Discontinuous Silicon Carbide Whiskers/Aluminum Metal Matrix Composites ASTM STP 964, ASTM, p. 277-284, 1988.

17. Hadianfard, M.J.; Hennes, G.; Healy, J.C.; Mai, Y.-W. Fracture Toughness Measurements and Failure Mechanisms of Metal Matrix Composites, Fatigue \& Fracture Engng Mater. Struct, v.17, n. 3, p. 253-263, 1994.

18. Larsson, L.H., ed., Advances in Elastic-Plastic Fracture Mechanics, Appld Science Publishers Ltd. Essex, England, 1980. 